Check for updates

Cite this: RSC Adv., 2019, 9, 3987

\title{
Preventive effect of oligonol on nitric oxide and reactive oxygen species production through regulation of nuclear factor kappa $B$ signaling pathway in RAW 264.7 macrophage cells against sodium nitroprusside
}

\begin{abstract}
Ah Young Lee, (D) Ji Won Choi, ${ }^{b}$ Takako Yokozawac and Eun Ju Cho (DD *a
Oligonol, a low-molecular weight polyphenol isolated from lychee fruit, has been shown to possess beneficial properties, including anti-oxidative, anti-diabetic, and hepatoprotective properties in vitro and in vivo. This study was performed to investigate the anti-inflammatory effects of oligonol using sodium nitroprusside (SNP)-stimulated RAW 264.7 macrophage cells. Our results demonstrated that exposure of SNP to RAW 264.7 cells significantly decreased cell viability, and increased nitric oxide (NO) and reactive oxygen species (ROS) production. However, treatment with oligonol inhibited cell death and suppressed the over-production of $\mathrm{NO}$ and ROS induced by SNP in a dose-dependent manner. Consistent with these findings, oligonol significantly downregulated the mRNA levels of pro-inflammatory mediators, inducible nitric oxide synthase and cyclooxygenase-2, when compared with the SNP-treated control group. Furthermore, suppression of nuclear factor- $\kappa \mathrm{B}(\mathrm{NF}-\kappa \mathrm{B})$ activation was also observed after treatment with oligonol in RAW 264.7 macrophage cells. These results suggest that oligonol attenuated SNP-induced oxidative stress and inflammatory responses via regulation of the NF- $\kappa$ B signalling pathway. On the basis of such potent anti-oxidant and anti-inflammatory properties, we propose that oligonol may contribute in the prevention and treatment of inflammation-related disorders.
\end{abstract}

Received 25th October 2018

Accepted 14th December 2018

DOI: $10.1039 / \mathrm{c} 8 \mathrm{ra0} 8867 \mathrm{e}$

rsc.li/rsc-advances

\section{Introduction}

Inflammation is a defence mechanism against harmful pathogens, such as bacteria, virus, and fungi, and macrophages are responsible for immune responses. ${ }^{1}$ During inflammation, activated-macrophage cells secrete pro-inflammatory cytokines and mediators, including nitric oxide (NO). NO plays a critical role in maintaining physiological homeostasis in the body. However, excessive NO can react with superoxide anion $\left(\mathrm{O}_{2}{ }^{-}\right)$to form toxic peroxynitrite $\left(\mathrm{ONOO}^{-}\right)$, which is implicated in the progression of degenerative and inflammatory diseases, such as cancer, diabetes, cardiovascular diseases, and Alzheimer's disease. ${ }^{2}$ Sodium nitroprusside (SNP), a potent NO donor, is widely used to elucidate the possible mechanisms of NOmediated oxidative stress and cell death. ${ }^{3-5}$ It has been reported that SNP induces phosphorylation of extracellular signalregulated kinase (ERK), p38, and c-Jun $\mathrm{NH}_{2}$-terminal kinase

\footnotetext{
${ }^{a}$ Department of Food Science and Nutrition, Kimchi Research Institute, Pusan National University, Busan 46241, Republic of Korea.E-mail: ejcho@pusan.ac.kr

${ }^{b}$ Technology Support Center, Korea Food Research Institute, Jeollabuk-do 55365, Republic of Korea

${ }^{c}$ Graduate School of Science and Engineering for Research, University of Toyama, Toyama 930-8555, Japan
}

(JNK) in macrophages. The activation of signalling pathways involving these mitogen-activated protein kinases (MAPKs) leads to the production of pro-inflammatory cytokines and mediators, such as $\mathrm{NO}$ and prostaglandin $\mathrm{E}_{2}\left(\mathrm{PGE}_{2}\right){ }^{6}$ In addition, a high level of SNP causes production of reactive oxygen species (ROS) and induction of apoptotic signalling pathway in a variety of cell types. ${ }^{5,7}$ Therefore, suppression of NO and ROS is a key modulator in inhibiting the progression of inflammation-related disorders. ${ }^{\mathbf{8}, 9}$

Oligonol, a phenolic compound derived from lychee fruit (Litchi chinensis Sonn.), is used as dietary supplement and pharmaceutical additive. In order to improve its absorption and bioavailability, oligonol from lychee extract is processed by an oligomerization reaction that converts high-molecular weight compounds into low-molecular weight oligomeric proanthocyanidins (including monomers, dimers, and trimers), indicating that oligonol contains high levels of proanthocyanidins, when compared with other plant sources. ${ }^{10}$ Previous reports have shown that oligonol exhibits anti-oxidative and antiinflammatory activity both in vitro and in vivo. Treatment with oligonol ameliorated hepatic damage against oxidative stress and lipid deposition in type 2 diabetic animal model. ${ }^{11}$ It has also been shown that oligonol exhibits protective effects against oxidative stress-induced inflammatory responses in glial cells. ${ }^{12}$ 
However, the effects of oligonol on SNP-induced cellular damage have not been studied yet. In the present study, we investigated the protective effects of oligonol against SNPinduced oxidative stress and NO formation in RAW 264.7 macrophage cells.

\section{Experimental}

\section{Preparation of oligonol}

Oligonol was provided by Amino Up Chemical Co., Ltd. (Sapporo, Japan), where it is produced from the lychee fruit (Litchi chinensis Sonn.) extract using a patented technology (international patent WO 2004/103988 AI). ${ }^{13}$ Briefly, dried Litchi chinensis Sonn. was extracted with $50 \%$ [volume by volume $(\mathrm{v} / \mathrm{v})$ ] ethanol. The filtrate was evaporated and passed through a DIAION HP-20 column, and eluted with ethanol. The eluate was then evaporated to dryness, yielding a dark brown powder. It was heated at $60{ }^{\circ} \mathrm{C}$ for $16 \mathrm{~h}$, filtered through a DIAION HP-20 column, washed with water, and eluted with $40 \%$ (v/v) ethanol. Evaporation of the eluate yielded a reddish-brown powder containing the monomeric and oligomeric proanthocyanidin mixture, referred to as oligonol. The composition of the oligonol used in this study (Batch no. OLF1202S) is shown in Table 1.

\section{Instruments and reagents}

RAW 264.7 macrophage cells were obtained from Korea Cell Line Bank (KCLB, Seoul, Korea). To culture cells, foetal bovine serum (FBS), Dulbecco's modified Eagle's medium (DMEM), and penicillin/streptomycin were supplied from Welgene (Daegu, Korea). SNP was purchased from Wako (Tokyo, Japan). Griess reagent, 3-(4,5-dimethylthiazol-2-yl)-2,5-diphenyl tetrazolium bromide (MTT), and dimethyl sulfoxide (DMSO) were purchased from Sigma Chemical Co. (St Louis, MO, USA).

\section{Cell culture}

The RAW 264.7 cells were cultured at $37{ }^{\circ} \mathrm{C}$ in a $\mathrm{CO}_{2}(5 \%)$ incubator in DMEM containing penicillin/streptomycin (1\%) and FBS (10\%) and were sub-cultured weekly using $0.05 \%$ trypsin-ethylenediaminetetraacetic acid (EDTA) in phosphate buffered saline.

\section{Cell viability}

After the cells reached confluence, they were seeded at $5 \times 10^{4}$ cells per well into 24-well plates and incubated for $2 \mathrm{~h}$, and then treated with oligonol $\left(5,10\right.$, and $\left.25 \mu \mathrm{g} \mathrm{mL}{ }^{-1}\right)$ for $24 \mathrm{~h}$. RAW 264.7 cells were then stimulated with SNP $(500 \mu \mathrm{M})$ for $24 \mathrm{~h}$. The cells were incubated with $1 \mathrm{~mL}$ of MTT solution $\left(5 \mathrm{mg} \mathrm{mL}^{-1}\right)$ for $4 \mathrm{~h}$ at $37^{\circ} \mathrm{C}$, and the medium containing MTT was removed. Then, the formazan crystals were dissolved in $1 \mathrm{~mL}$ of DMSO, and viable cells were quantified by measuring the absorbance at $540 \mathrm{~nm}^{.14}$

\section{Measurement of NO production}

NO production was evaluated by quantifying the nitrite accumulation in the medium treated with the Griess reagent. To measure nitrite levels, the cell supernatants were added with a same volume of the Griess reagent. And then, the nitrite concentration was measured using microplate spectrophotometer (BMG LAB-TECH, Ortenberg, Germany) at a wave length of $540 \mathrm{~nm}^{.15}$

\section{Measurement of ROS production}

The ROS scavenging activity of oligonol was measured using dichlorodihydrofluorescein diacetate (DCFH-DA). ${ }^{16}$ RAW 264.7 cells were incubated with oligonol $\left(5,10\right.$, and $\left.25 \mu \mathrm{g} \mathrm{mL}^{-1}\right)$ for $24 \mathrm{~h}$ at $37^{\circ} \mathrm{C}$, followed by treatment with SNP $(500 \mu \mathrm{M})$ for another $24 \mathrm{~h}$. Florescence was read for $60 \mathrm{~min}$, at wavelengths of

Table 1 Composition of oligonol

\begin{tabular}{|c|c|c|c|}
\hline Components & & & Composition (\%) \\
\hline \multirow[t]{11}{*}{ Total polyphenols } & & & 91.49 \\
\hline & Monomers (flavin-3-ols) & Catechin + epicatechin & 6.94 \\
\hline & & Epigallocatechin & 1.36 \\
\hline & & Epigallocatechin gallate & 7.02 \\
\hline & Dimers (procyanidins) & Procyanidins A1 & 6.21 \\
\hline & & Procyanidins A2 & 6.59 \\
\hline & & Procyanidins B1 & 0.43 \\
\hline & & Procyanidins B2 & 1.98 \\
\hline & & Epicatechin-epigallocatechin gallate & 1.45 \\
\hline & Trimers & Epicatechin-procyanidin A2 & 4.53 \\
\hline & Other phenolic compounds & & 54.98 \\
\hline Moisture content & & & 1.57 \\
\hline Protein & & & 1.70 \\
\hline Total fats & & & 0.30 \\
\hline Ash & & & 0.17 \\
\hline Sodium & & & 0.05 \\
\hline Sugar & & & 2.97 \\
\hline Unknown & & & 1.75 \\
\hline Total & & & 100 \\
\hline
\end{tabular}


Table 2 Primers and conditions used in PCR

\begin{tabular}{|c|c|c|}
\hline mRNA & Primer sequence & PCR condition \\
\hline \multirow[t]{2}{*}{ iNOS } & F: CCT-CCT-CCA-CCC-TAC-CAA-GT & $55{ }^{\circ} \mathrm{C}$, cycle: 35 \\
\hline & R: CAC-CCA-AAG-TGC-CTC-AGT-CA & \\
\hline & T: CTT-CTG-CAG-TCC-AGG-TTC-AA & \\
\hline \multirow[t]{2}{*}{ NF- $\kappa \mathrm{B}$} & F: GCA-GCC-TAT-CAC-CAA-CTC T & $48{ }^{\circ} \mathrm{C}$, cycle: 35 \\
\hline & R: TAC-TCC-TTC-TTC-ACC A & \\
\hline
\end{tabular}

$480 \mathrm{~nm}$ for excitation and $535 \mathrm{~nm}$ for emission, using a florescence plate reader (BMG LABTECH, Ortenberg, Germany).

\section{Reverse transcription-polymerase chain reaction (RT-PCR)}

Total RNA was isolated using a Trizol reagent (Invitrogen, Carlsbad, CA) according to the manufacturer's instructions. Cells were lysed using Trizol reagent and transferred to microfuge tubes. RNA was reverse-transcribed into cDNA which was amplified using PCR. The primers and amplification conditions are listed in Table 2. PCR products were analysed on $1 \%$ agarose gels, and bands were visualized using an LED slider imager (Maestrogen, Las Vegas, NV, USA).

\section{Statistical analysis}

Data are expressed as the mean \pm SD. Statistical significance was measured by one-way ANOVA, followed by Duncan's post hoc tests $(P<0.05)$.

\section{Results and discussion}

Under inflammatory condition, NO may combine with $\mathrm{O}_{2}{ }^{-}$to form $\mathrm{ONOO}^{-}$, which is implicated in damage to lipids, proteins, and nucleic acids. Previous studies have demonstrated that a large amount of NO induces expression of pro-inflammatory cytokines and enzymes associated with various inflammatory disorders. ${ }^{17,18}$ In addition, NO can react with other free radicals, which are involved in oxidative or nitrosative stress to cells. ${ }^{19}$ Therefore, inhibition of excessive NO generation is crucial in the prevention and treatment of inflammatory diseases. SNP, an NO donor, has been recognized as an inducer of apoptosis in various cell types, including macrophage cells. ${ }^{20,21}$ It has already been suggested that SNP is a pro-oxidant agent that induces cellular impairment and cytotoxicity via the release of $\mathrm{NO}^{22}$ Geetha et al. ${ }^{23}$ has also reported that SNP induced cytotoxicity and led to the production of ROS in macrophages. Much attention has been focused on natural sources containing polyphenols and flavonoids, which exert anti-inflammatory effects by suppression of NO production or pro-inflammatory cytokines. ${ }^{24-26}$ In order to investigate the effects of oligonol, which is a low molecular weight polyphenol obtained from Litchi, on inflammatory responses, we evaluated cell viability, NO, and ROS production, as well as the levels of mRNA expression of inflammation-related genes in SNP-stimulated RAW 264.7 macrophage cells.
Cell viability was detected by the mitochondrial reduction of MTT in SNP-induced RAW 264.7 cells treated with different concentrations of oligonol. As previously reported, SNP can lead to cell cytotoxicity and over-production of NO and ROS in macrophages. ${ }^{27}$ Consistent with previous evidence, exposure to SNP reduced cell viability (29.17\%), when compared with the control group (100\%), indicating that SNP induces cell death in RAW 264.7 cells. However, treatment with 5,10 , and $25 \mu \mathrm{g} \mathrm{mL}$ oligonol significantly increased the cell viability to $42.77 \%$, $81.28 \%$, and $97.87 \%$, respectively (Fig. 1).

To investigate the anti-inflammatory properties of oligonol against SNP, we examined NO production in RAW 264.7 macrophage cells. Cells were pre-treated with various concentrations of oligonol $\left(5,10\right.$, and $\left.25 \mu \mathrm{g} \mathrm{mL} \mathrm{m}^{-1}\right)$ for $24 \mathrm{~h}$, and then stimulated with the $500 \mu \mathrm{M}$ SNP for another $24 \mathrm{~h}$. The levels of NO in the cell culture supernatants were determined by Griess reagent assay. As shown in Fig. 2, SNP significantly enhanced NO production when compared with the control group (from $5.0 \mu \mathrm{M}$ to $26.6 \mu \mathrm{M}$ ), whereas oligonol treatment was shown to significantly suppress SNP-induced NO production in a concentration-dependent manner. In particular, treatment with $25 \mu \mathrm{g} \mathrm{mL} \mathrm{m}^{-1}$ oligonol markedly inhibited over-production of NO from $26.64 \%$ to $13.78 \%$.

Activated macrophages have been known to increase oxidative stress and reduce antioxidant enzymes that prevent cell or tissue damage. ${ }^{28}$ Increasing evidences have indicated that SNP-

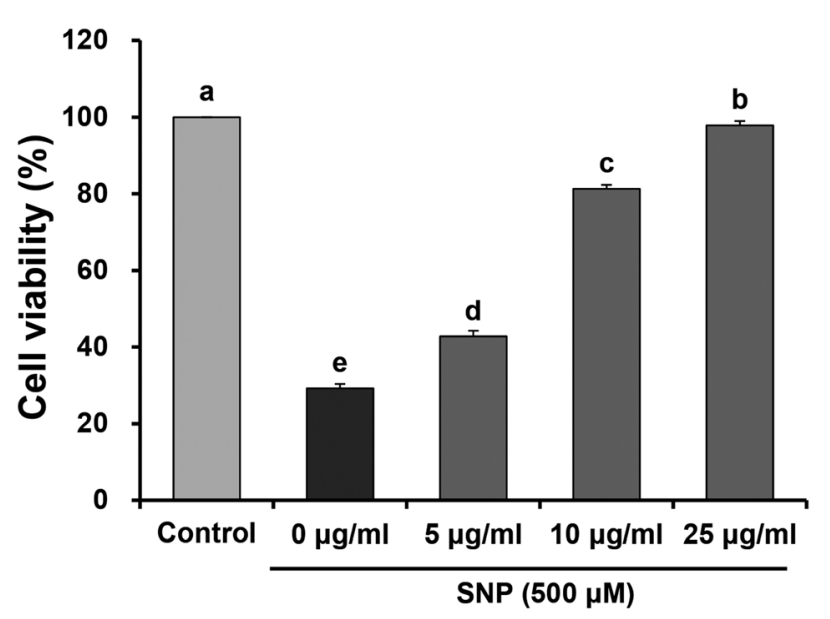

Fig. 1 Effects of oligonol on cell viability in RAW 264.7 macrophage cells treated with SNP. Values are presented as mean \pm SD. ${ }^{a-e}$ Means with different letters are significantly different $(P<0.05)$ as determined by Duncan's multiple range test. 


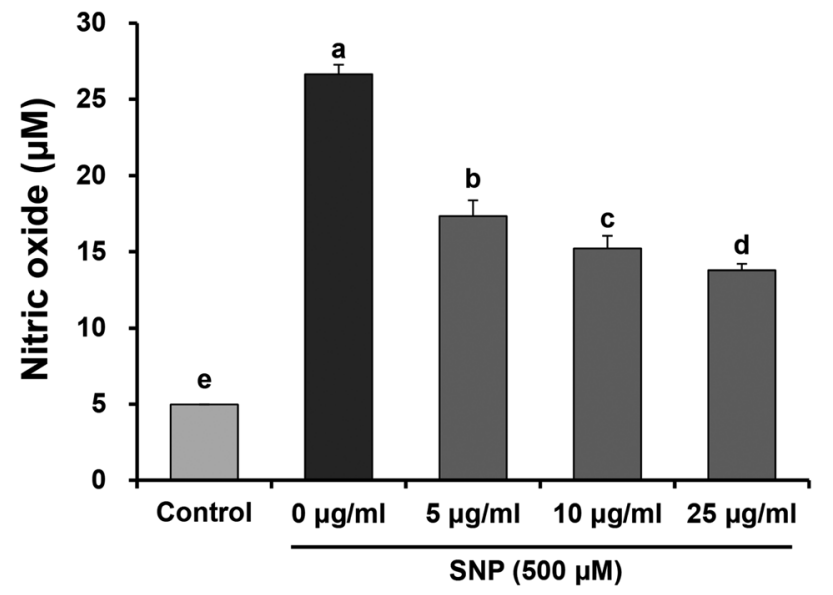

Fig. 2 Effects of oligonol on NO production in RAW 264.7 macrophage cells treated with SNP. Values are presented as mean \pm SD. ${ }^{a-e}$ Means with different letters are significantly different $(P<0.05)$ as determined by Duncan's multiple range test.

induced NO upregulates endogenous ROS generation, which, in turn, induces cellular apoptosis. ${ }^{29}$ Oligonol has also been shown to exhibit protective effects against oxidative stress in vitro and in vivo. ${ }^{12,30,31}$ However, it remains unclear whether oligonol prevents SNP-induced ROS production. We measured the protective effects of oligonol on ROS production due to SNP, using DCFH-DA assay. Fig. 3 indicates that SNP-stimulated RAW 264.7 cells exhibited higher ROS formation (100\%) when compared with the normal group (67.6\%). However, oligonol effectively attenuated ROS levels when compared with the SNPtreated control group. The ROS levels of the cells treated with 5 , 10 , and $25 \mu \mathrm{g} \mathrm{mL}^{-1}$ of oligonol group were $89.9 \%, 83.6 \%$, and $82.9 \%$, respectively. These results can be supported by previous evidence showing that oligonol treatment increased superoxide dismutase activity and attenuated ROS levels against high glucose in vascular endothelial cells. ${ }^{32}$ Therefore, our findings suggested that oligonol has antioxidant properties, acting as scavengers of ROS generated by SNP.

Under inflammatory progression, iNOS and COX-2 are significantly up-regulated, which promotes NO generation. Abnormalities in NO production by iNOS led to cytotoxicity, which is implicated in the pathogenesis of various inflammatory disorders, including cardiovascular disease, neurodegenerative disease, and cancer. ${ }^{3-35}$ Thereby, we performed RT-PCR for observation of mRNA expression levels of iNOS and COX-2 in SNP-treated RAW 264.7 macrophage cells. The data indicated that the mRNA expression levels of iNOS and COX-2 induced by SNP in macrophages were suppressed after oligonol treatment (Fig. 4). In particular, treatment with $25 \mu \mathrm{g} \mathrm{mL} \mathrm{m}^{-1}$ oligonol significantly decreased mRNA levels of iNOS and COX-2 when compared with the single SNP-treated group. Fujii et al. ${ }^{36}$ also showed that oligonol inhibited high glucose-induced iNOS and COX-2 protein expressions. These results suggested that suppression of pro-inflammatory mediators, iNOS and COX-2, may contribute to inhibitory effects of oligonol against NO production induced by SNP.
(A)

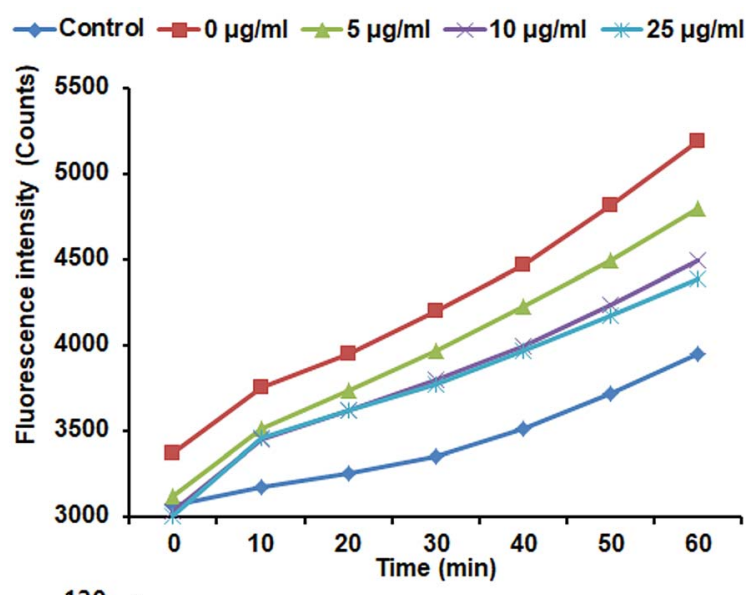

(B)

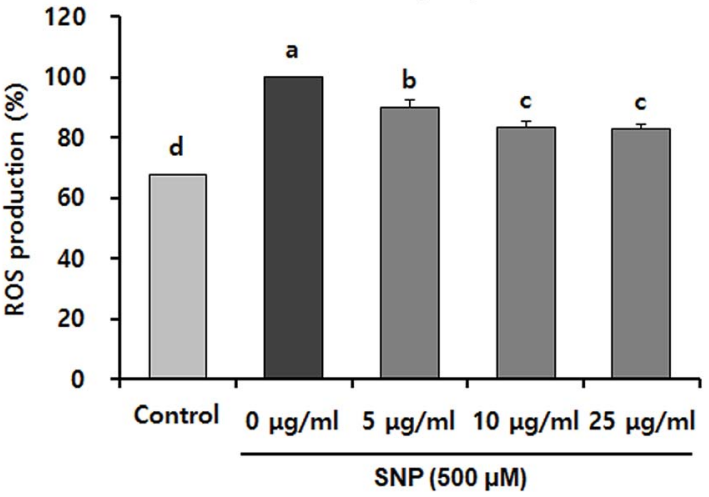

Fig. 3 Effects of oligonol on ROS production in RAW 264.7 macrophage cells treated with SNP. (A) Change in intensity of ROS fluorescence with time after oligonol treatment. (B) The production of ROS in cells treated with oligonol. Values are presented as mean \pm SD. ${ }^{a-d}$ Means with different letters are significantly different $(P<0.05)$ as determined by Duncan's multiple range test.

$\mathrm{NF}-\kappa \mathrm{B}$ is an important upstream transcription factor for regulation of iNOS and COX-2 expression. Before activation, NF$\kappa \mathrm{B}$ is combined with inhibitor $\kappa \mathrm{B}(\mathrm{I} \kappa \mathrm{B})$, an inhibitory protein. When exposed to extracellular stimuli, such as $\mathrm{SNP}, \mathrm{I} \kappa \mathrm{B} \alpha$ is phosphorylated and dissociates from NF- $\kappa \mathrm{B} .{ }^{37}$ The free NF- $\kappa \mathrm{B}$ is translocated from cytoplasm into the nucleus to activate the inflammation-related genes, such as iNOS and COX-2. ${ }^{38}$ In addition, ROS can regulate production of these proinflammatory mediators via NF- $\kappa \mathrm{B}$ dependent mechanisms. In the present study, we therefore investigated whether oligonol affects NF- $\kappa$ B activation in SNP-induced RAW 264.7 macrophage cells. Our data showed that treatment of SNP significantly over-expressed the mRNA levels of NF- $\kappa \mathrm{B}$ compared to control group; however, treatment with oligonol significantly inhibited NF- $\kappa$ B expression (Fig. 5). Several evidences have demonstrated that treatment of oligonol downregulated the mRNA levels of pro-inflammatory cytokines, such as tumor necrosis factor$\alpha$ (TNF- $\alpha$ ) and interleukin (IL)-1 $\beta$, by inhibition of NF- $\kappa$ B activity in $\mathrm{CCl}_{4}$-induced rat model. ${ }^{39}$ Moreover, oligonol suppressed IL6 and TNF- $\alpha$ production mediated by NF- $\kappa \mathrm{B}$ activation in human monocytes. ${ }^{40}$ According to Yamanishi (2014), oligonol decreased the mRNA levels of NF- $\kappa \mathrm{B}$ target genes cytokines and 

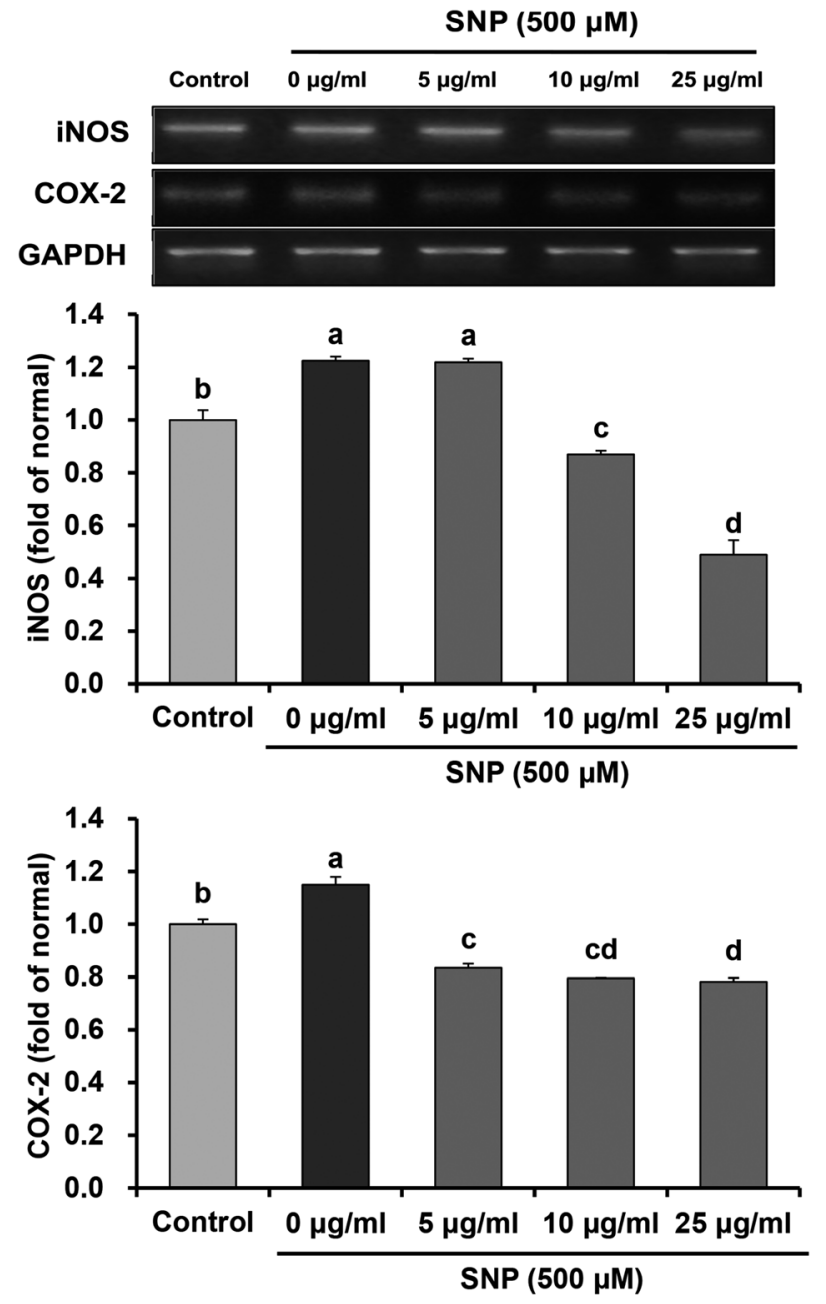

Fig. 4 Effects of oligonol on iNOS and COX-2 mRNA expression in RAW 264.7 macrophage cells treated with SNP. Values are presented as mean $\pm \mathrm{SD} .{ }^{a-d}$ Means with different letters are significantly different $(P<0.05)$ as determined by Duncan's multiple range test. GAPDH was used as a control gene for normalization of relative gene expression levels.

chemokines, TNF- $\alpha . .^{\mathbf{4 1}}$ Oligonol treatment also markedly reduced the lipopolysaccharide-induced mRNA expression of IL-1 $\beta$, IL-6, and TNF- $\alpha$ in RAW 264.7 cells. ${ }^{42}$ Therefore, oligonol may inhibit NF- $\kappa \mathrm{B}$ activation and nuclear translocation to suppress the expression of these inflammatory cytokines.

Lychee polyphenols have catechin-type monomers and oligomers of proanthocyanidins. However, proanthocyanidins with a high-molecular-weight are insoluble in water and making them to utilize in the food industry is difficult. In addition, they have high-molecular-weight and their absorption is limited in the body. Previous research demonstrated that high-molecularweight proanthocyanidin can be converted into low-molecularweight proanthocyanidin under acidic conditions. According to method of Tanaka et al., catechin monomers are replaced at the C-4 position of proanthocyanidin fragment with a highmolecular-weight, leading to generate low-molecular-weight proanthocyanidins. ${ }^{43}$ Therefore, the contents of oligomers in a typical polyphenol polymer are less than $10 \%$, whereas oligonol, which is produced by oligomerizing polyphenol

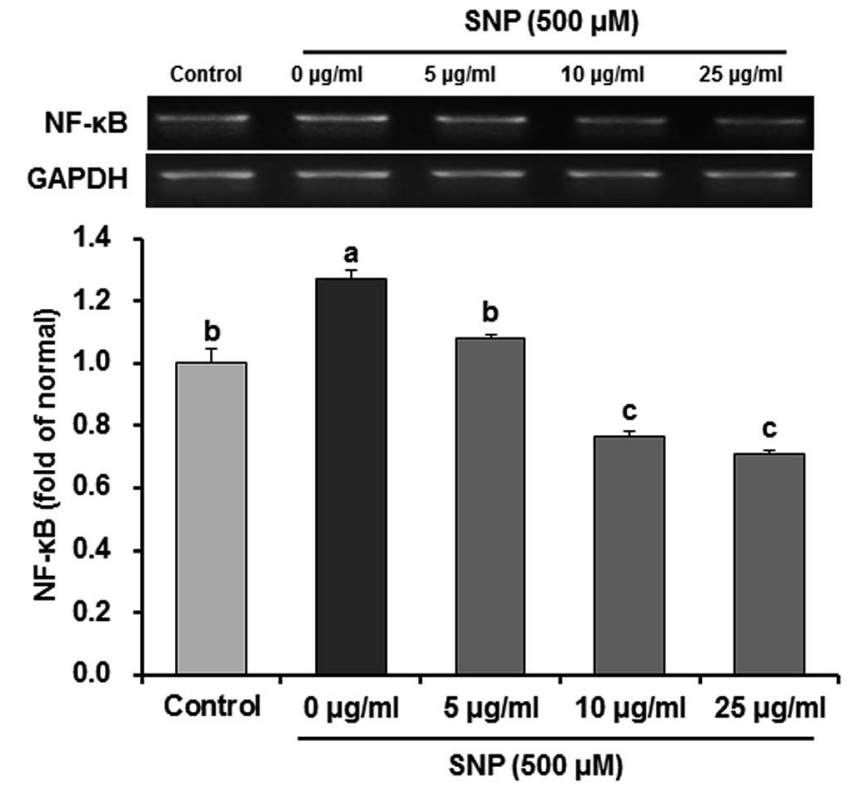

Fig. 5 Effects of oligonol on NF- $\mathrm{BB}$ mRNA expression in RAW 264.7 macrophage cells treated with SNP. Values are presented as mean \pm SD. ${ }^{a-c}$ Means with different letters are significantly different $(P<0.05)$ as determined by Duncan's multiple range test. GAPDH was used as a control gene for normalization of relative gene expression levels.

polymers derived from lychee fruit, consists mainly of $15.3 \%$ monomeric flavan-3-ols [i.e., (+)-catechin, (-)-epicatechin, (-)-epicatechin 3-gallate, and (-)-epigallocatechin gallate], which combined constitute approximately $16.7 \%$ of dimers and $4.5 \%$ of trimmers surpassing equivalent products. ${ }^{44}$

There are accumulating evidences that oligonol exerts antiinflammatory properties in vivo. Our previous study revealed that supplementation of oligonol suppressed the production of lipid peroxidation and NO production, which are mediator of inflammation, in the amyloid $\beta$-injected mice brain. ${ }^{45}$ Park et al. demonstrated that protein expression of pro-inflammatory cytokine including TNF- $\alpha$ and oxidative stress-mediated JNK signaling were markedly down-regulated by oligonol treatment. ${ }^{46}$ In addition, administration of oligonol inhibited oxidative stress and inflammation through the inhibition of ROS generation, lipid peroxidation, and down-regulation of NF$\kappa \mathrm{B}$ and iNOS protein expression. ${ }^{11}$ Oligonol also significantly inhibited UVB-induced COX-2 expression in mouse model. ${ }^{47,48}$ To further understand effect of oligonol, a study involving the pro-inflammatory cytokines and mechanisms in vivo should be performed to determine the protective role of oligonol in SNPinduced inflammatory responses, our results suggest that anti-inflammatory effects of oligonol through the regulation of NF- $\kappa \mathrm{B}$ signalling pathway may be the possible mechanism responsible for the inhibition of $\mathrm{NO}$ and ROS production in SNP-stimulated RAW 264.7 macrophage cells.

\section{Conclusions}

Our findings demonstrated that oligonol increased cell viability and inhibited NO and ROS production in SNP-induced RAW 264.7 macrophage cells by suppressing the levels of pro- 
inflammatory mediators, iNOS, and COX-2. Therefore, the protective effects of oligonol against SNP-mediated cellular damage may be mediated via regulation of NF- $\kappa \mathrm{B}$ activation. Although further studies are needed to investigate the precise mechanisms of oligonol-induced regulation of inflammatory signalling pathway, our findings suggest that oligonol exhibits therapeutic potential against inflammation-related diseases.

\section{Conflicts of interest}

There are no conflicts to declare.

\section{References}

1 N. Fujiwara and K. Kobayashi, Macrophages in inflammation, Curr. Drug Targets: Inflammation Allergy, 2005, 4, 281-286.

2 S. Moncada, R. M. Palmer and E. A. Higgs, Nitric oxide: physiology, pathophysiology and pharmacology, Pharmacol. Rev., 1991, 43, 109-142.

3 S. Cardaci, G. Filomeni, G. Rotilio and M. R. Ciriolo, Reactive oxygen species mediate p53 activation and apoptosis induced by sodium nitroprusside in SH-SY5Y cells, Mol. Pharmacol., 2008, 74, 1234-1245.

4 M. Pytlowany, J. B. Strosznajder, H. Jeśko, M. Cakala and R. P. Strosznajder, Molecular mechanism of PC12 cell death evoked by sodium nitroprusside, a nitric oxide donor, Acta Biochim. Pol., 2008, 55, 339-347.

5 Y. Zhang and B. Zhao, Green tea polyphenols enhance sodium nitroprusside-induced neurotoxicity in human neuroblastoma SH-SY5Y cells, J. Neurochem., 2003, 86, 1189-1200.

6 H. J. Park, H. J. Lee, M. S. Choi, D. J. Son, H. S. Song, M. J. Song, J. M. Lee, S. B. Han, Y. Kim and J. T. Hong, JNK pathway is involved in the inhibition of inflammatory target gene expression and NF-kappaB activation by melittin, J. Inflammation, 2008, 5, 7.

7 W. Zheng, C. M. Chong, H. Wang, X. Zhou, L. Zhang, R. Wang, Q. Meng, P. Lazarovici and J. Fang, Artemisinin conferred ERK mediated neuroprotection to PC12 cells and cortical neurons exposed to sodium nitroprusside-induced oxidative insult, Free Radical Biol. Med., 2016, 97, 158-167.

8 H. Ischiropoulos, L. Zhu and J. S. Beckman, Peroxynitrite formation from macrophage-derived nitric oxide, Arch. Biochem. Biophys., 1992, 298, 446-451.

9 C. C. Wu and C. Thiemermann, Biological control and inhibition of induction of nitric oxide synthase, Methods Enzymol., 1996, 268, 408-420.

10 H. Fujii, B. Sun, H. Nishioka, A. Hirose and O. I. Aruoma, Evaluation of the safety and toxicity of the oligomerized polyphenol oligonol, Food Chem. Toxicol., 2007, 45, 378-387.

11 J. S. Noh, C. H. Park and T. Yokozawa, Treatment with oligonol, a low-molecular polyphenol derived from lychee fruit, attenuates diabetes-induced hepatic damage through regulation of oxidative stress and lipid metabolism, $\mathrm{Br} . \mathrm{J}$. Nutr., 2011, 106, 1013-1022.
12 J. H. Ahn, J. W. Choi, J. M. Choi, T. Maeda, H. Fujii, T. Yokozawa and E. J. Cho, Protective role of oligonol from oxidative stress-induced inflammation in C6 glial cell, Nutr. Res. Pract., 2015, 9, 123-128.

13 G. I. Nonaka, B. Sun, L. Tuan, T. Nakagawa, H. Fujii and Y. J. Surh, Sulfur-containing proanthocyanidin oligomer composition and process for producing the same, Int. Pat., EP1524270 A1, 2004.

14 T. Mosmann, Rapid colorimetric assay for cellular growth and survival: application to proliferation and cytotoxicity assays, J. Immunol. Methods, 1983, 65, 55-63.

15 V. M. Dirsch, H. Stuppner and A. M. Vollmar, The Griess assay. Suitable for a bioguided fractionation of antiinflammatory plant extract?, Planta Med., 1998, 64, 423-426.

16 R. Cathcart, E. Schwiers and B. N. Ames, Detection of picomole levels of hydroperoxides using a fluorescent dichlorofluorescein assay, Anal. Biochem., 1983, 134, 111116.

17 K. D. Kröncke, K. Fehsel and V. Kolb-Bachofen, Nitric oxide: cytotoxicity versus cytoprotection: how, why, when, and where?, Nitric Oxide, 1997, 1, 107-120.

18 F. S. Laroux, K. P. Pavlick, I. N. Hines, S. Kawachi, H. Harada, S. Bharwani, J. M. Hoffman and M. B. Grisham, Role of nitric oxide in inflammation, Acta Physiol. Scand., 2001, 173, 113118.

19 S. Luperchio, S. Tamir and S. R. Tannenbaum, NO-induced oxidative stress and glutathione metabolism in rodent and human cells, Free Radical Biol. Med., 1996, 21, 513-519.

20 H. Y. Jang, S. J. Ji, Y. H. Kim, H. Y. Lee, J. S. Shin, H. T. Cheong, J. T. Kim, I. C. Park, H. S. Kong, C. K. Park and B. K. Yang, Antioxidative effects of astaxanthin against nitric oxide-induced oxidative stress on cell viability and gene expression in bovine oviduct epithelial cell and the developmental competence of bovine IVM/IVF embryos, Reprod. Domest. Anim., 2010, 45, 967-974.

21 K. Y. Kim, H. S. Lee, S. S. Min and G. H. Seol, Neuroprotective effect of (-)-linalool against sodium nitroprusside-induced cytotoxicity, Med. Chem., 2015, 5, 178-182.

22 P. Rauhala, A. Khaldi, K. P. Mohanakumar and C. C. Chiueh, Apparent role of hydroxyl radicals in oxidative brain injury induced by sodium nitroprusside, Free Radical Biol. Med., 1998, 24, 1065-1073.

23 S. Geetha, M. S. Ram, V. Shigh, G. Ilavazhagan and R. C. Sawhney RC, Effect of seabuckthorn on sodium nitroprusside-induced cytotoxicity in murine macrophages, Biomed. Pharmacother., 2002, 56, 463-467.

24 O. K. Kim, A. Murakami, Y. Nakamura and H. Ohigashi, Screening of edible Japanese plants for nitric oxide generation inhibitory activities in RAW 264.7 cells, Cancer Lett., 1998, 125, 199-207.

25 F. Sheu, H. H. Lai HH and G. C. Yen, Suppression of soy isoflavones on nitric oxide production in RAW 264.7 macrophages, J. Agric. Food Chem., 2001, 49, 1767-1772.

26 J. Taira, H. Nanbu and K. Ueda, Nitric oxide-scavenging compounds in Agrimonia pilosa Ledeb on LPS-induced RAW264.7 macrophages, Food Chem., 2009, 115, 1221-1227. 
27 H. Chang, S. Y. Tsai, Y. Chang, T. L. Chen and R. M. Chen, Therapeutic concentrations of propofol protects mouse macrophages from nitric oxide-induced cell death and apoptosis, Can. J. Anaesth., 2002, 49, 477-480.

28 M. Ye, Q. Wang, W. Zhang, Z. Li, Y. Wang and R. Hu, Oroxylin A exerts anti-inflammatory activity on lipopolysaccharide-induced mouse macrophage via $\mathrm{Nrf} 2 /$ ARE activation, Biochem. Cell Biol., 2014, 92, 337-348.

29 G. J. Wu, T. G. Chen, H. C. Chang, W. T. Chiu, C. C. Chang and R. M. Chen, Nitric oxide from both exogenous and endogenous sources activates mitochondria-dependent events and induces insults to human chondrocytes, J. Cell. Biochem., 2007, 101, 1520-1531.

30 C. H. Park, J. Y. Lee, M. Y. Kim, S. H. Shin, S. S. Roh, J. S. Choi, H. Y. Chung, Y. O. Song, Y. S. Shin and T. Tokozawa, Oligonol, a low-molecular-weight polyphenol derived from lychee fruit, protects the pancreas from apoptosis proliferation via oxidative stress in streptozotocin-induced diabetic rats, Food Funct., 2016, 7, 3056-3063.

31 C. H. Park, J. Y. Lee, S. H. Shin, M. Y. Kim, E. S. Lee, Y. S. Shin, Y. O. Kim, S. W. Lee, J. S. Choi and T. Yokozawa, Oligonol attenuates diabetes-induced pancreatic damage by inhibiting inflammatory responses via oxidative stress-dependent MAPK/NF- $\kappa \mathrm{B}$ signaling, Preprints, 2017, 201705208, DOI: 10.20944/ preprints201705.0208.v1.

32 X. H. Zhang, H. Yokoo, H. Nishioka, H. Fujii, N. Matsuda, T. Hayashi and Y. Hattori, Beneficial effect of the oligomerized polyphenol oligonol on high glucose-induced changes in eNOS phosphorylation and dephosphorylation in endothelial cells, Br. J. Pharmacol., 2010, 159, 928-938.

33 L. Ying and L. J. Hofseth, An emerging role for endothelial nitric oxide synthase in chronic inflammation and cancer, Cancer Res., 2007, 67, 1407-1410.

34 G. C. Brown, Nitric oxide and neuronal death, Nitric Oxide, 2010, 23, 153-165.

35 L. Rochette, j. Lorin, M. Zeller, J. C. Guilland, L. Lorgis, Y. Cottin and C. Vergely, Nitric oxide synthase inhibition and oxidative stress in cardiovascular disease: possible therapeutic targets?, Pharmacol. Ther., 2013, 140, 239-257.

36 H. Fujii, T. Yokozawa, Y. A. Kim, C. Tohda and G. Nonaka, Protective effect of grape seed polyphenols against high glucose-induced oxidative stress, Biosci., Biotechnol., Biochem., 2006, 70, 2104-2111.

37 P. A. Baeuerle, IkappaB-NF-kappaB structure: at the interface of inflammation control, Cell, 1998, 95, 729-731.
38 Q. Li and I. M. Verma, NF-kappaB regulation in the immune system, Nat. Rev. Immunol., 2002, 2, 725-734.

39 J. Bak, N. K. Je, H. Y. Chung, T. Yokozawa, S. Yoon and J. O. Moon, Oligonol ameliorates $\mathrm{CCl}_{4}$-induced liver injury rats via the NF-kappa B and MAPK signaling pathway, Oxid. Med. Cell. Longevity, 2016, 2016, 3935841.

40 N. Lee, M. S. Shin, Y. Kang, K. Park, T. Maeda, H. Nishioka, H. Fujii and I. Kang I, Oligonol, a lychee fruit-derived lowmolecular from of polyphenol mixture, suppresses inflammatory cytokine production from human monocytes, Hum. Immunol., 2016, 77, 512-515.

41 R. Yamanishi, E. Yoshigai, T. Okuyama, M. Mori, H. Murase, T. Machida, T. Okumura and M. Nishizawa, The antiinflammatory effects of flavanol-rich lychee fruit extract in rat hepatocytes, PLoS One, 2014, 9, e93818.

42 H. W. Yum, X. Zhong, J. Park, H. K. Na, N. Kim, H. S. Lee and Y. J. Surh, Oligonol inhibits dextran sulfate sodium-induced colitis and colonic adenoma formation in mice, Antioxid. Redox Signaling, 2013, 19, 102-114.

43 T. Tanaka, N. Yoshitake, P. Zhao, Y. Matsuo, I. Kouno and G. Nonaka, Production of oligomeric proanthocyanidins by fragmentation of polymers, Jpn. J. Food Chem., 2007, 14, 134-139.

44 K. Kitadate, K. Homma, A. Roberts and T. Maeda, Thirteenweek oral dose toxicity study of oligonol containing oligomerized polyphenols extracted from lychee and green tea, Regul. Toxicol. Pharmacol., 2014, 68, 140-146.

45 Y. Y. Choi, M. Takahiro, H. Fujii, T. Yokozawa, H. Y. Kim, E. J. Cho and T. Shibamoto, Oligonol improves memory and cognition under an amyloid $\beta_{25-35}$-induced Alzheimer's mouse model, Nutr. Res., 2014, 34, 595-603.

46 C. H. Park, T. Yokozawa and J. S. N. Oligonol, a lowmolecular-weight polyphenol derived from lychee fruit, attenuates diabetes-induced renal damage through the advanced glycation end product-related pathway in $\mathrm{d} \mathrm{b} /$ d b mice, J. Nutr., 2014, 144, 1150-1157.

47 J. K. Kundu, E. J. Chang, H. Fujii, B. Sun and Y. J. Surh, Oligonol inhibits UVB-induced COX-2 expression in HR-1 hairless mouse skin-AP-1 and C/EBP as potential upstream targets, Photochem. Photobiol., 2008, 84, 399-406.

48 J. K. Kundu, K. S. Choi, H. Fujii, B. Sun and Y. J. Surh, Oligonol, a lychee fruit-derived low molecular weight polyphenol formulation, inhibits UVB-induced cyclooxygenase- 2 expression, and induces $\mathrm{NAD}(\mathrm{P}) \mathrm{H}$ : quinone oxidoreductase-1 expression in hairless mouse skin, J. Funct. Foods, 2009, 1, 98-108. 